\title{
Prevalence of Depression in Patients with Juvenile Idiopathic Arthritis Presenting at a Tertiary Care Hospital
}

\author{
Saira Bano ${ }^{1}$, Khalid Bosan ${ }^{2}$, Sadia Khurshid ${ }^{1}$, Uzma Rasheed ${ }^{1}$, Alam Zeb ${ }^{1}$, Shazia Zammurrad ${ }^{1}$ \\ 1. Rheumatology, Pakistan Institute of Medical Sciences, Islamabad, PAK 2. Radiology, Pakistan Atomic Energy \\ Commission General Hospital, Islamabad, PAK
}

Corresponding author: Saira Bano, sairabano56326@gmail.com

\section{Abstract \\ Background and objective}

Juvenile idiopathic arthritis (JIA) is an idiopathic autoimmune rheumatic disorder in children. JIA has been associated with depression and has a negative psychological impact on patients' quality of life. The aim of the study is to determine the prevalence of depression in patients with JIA presenting at a tertiary care hospital in Islamabad, Pakistan.

\section{Materials and methods}

This cross-sectional study, conducted at the Department of Rheumatology, Pakistan Institute of Medical Sciences, Islamabad, Pakistan, included 100 children aged $>6$ years who had been diagnosed with JIA according to the 2004 revised International League of Associations for Rheumatology classification. Physical disability was measured using the Childhood Health Assessment Questionnaire disability index (CHAQ-DI), whereas depression was assessed by measuring their Center for Epidemiological Studies Depression Scale for Children (CES-DC) scores. Results were analyzed using IBM SPSS Statistics for Windows, Version 20.0. (Armonk, NY: IBM Corp.), with p-values $\leqslant 0.05$ considered statistically significant.

\section{Results}

The 100 patients included 54 male patients (mean age, $16.3 \pm 4.9$ years) and 46 female patients (mean age, $18.6 \pm 5.1$ years). CES-DC scores showed that 72 patients with JIA had significant depression. Of these 72 patients, 50 (69.4\%) had mild, 21 (29.2\%) had moderate, and one (1.4\%) had severe disability according to CHAQ-DI criteria. Age was the only effect modifier significantly associated with significant depression in patients with JIA $(\mathrm{P}<0.05)$.

\section{Conclusion}

Received 01/17/2020 Review began 01/24/2020 Review ended 01/25/2020 Published 01/28/2020

\section{() Copyright 2020}

Bano et al. This is an open access article distributed under the terms of the Creative Commons Attribution License CC-BY 3.0., which permits unrestricted use, distribution, and reproduction in any medium, provided the original author and source are credited.
A cross sectional survey was carried out to find prevalence of depression in children with JIA. Physical disability and depression were measured using standardized tools. The percentage of significant depression among children with JIA is very high in our local population and was significantly associated with disease severity. Our findings emphasize the need to initiate early and prompt measures to prevent depression and reduce overall morbidity in patients with JIA.

Categories: Internal Medicine, Pediatrics, Rheumatology

Keywords: juvenile idiopathic arthritis, depression, burden of disease

\section{Introduction}

Juvenile idiopathic arthritis (JIA) is one of the most frequent types of rheumatologic disorders in pediatric patients aged younger than 16 years [1]. JIA consists of a heterogeneous group of chronic disorders of unknown etiology encompassing all forms of arthritis. JIA is characterized by the non-infectious inflammation of synovial membranes of the joints and connective tissues that lasts for at least six weeks [2, 3]. Its global incidence has been reported to range from one to 23 per 100,000 persons per year, and its prevalence ranges from seven to 400 per 100,000 children [4-6]. Although the exact etiopathogenesis of JIA remains unclear, it may be due to immune dysregulation secondary to various environmental and genetic factors [7]. Some children experience the symptoms of JIA for a shorter time, whereas others experience its symptoms and their consequences for their entire lives [8].

During their course of the disease, children with JIA may also experience frequent episodes of depression and other psychosocial disorders $[9,10]$. Depressive symptoms among these children may be conditioned by their restricted daily activities, altered body images, growth retardation, visual symptoms, limitations in leisure time, and frequent visits to the doctor [11]. Psychological problems, especially depression, are more 


\section{Cureus}

prevalent in patients with JIA than in normal individuals, with the incidence of clinically significant depression ranging from $7 \%$ to $36 \%$ in children with JIA [12-14]. To further assess the incidence of this commonly occurring psychological disorder in patients with JIA, and to better understand the significant effect modifiers associated with the increased prevalence of depression in these patients, the present study assessed the burden of depression in JIA patients in the local population of Islamabad, Pakistan. The results of this study may guide rheumatologists to initiate early and prompt measures to prevent depression in this population, reducing overall morbidity in patients with JIA.

\section{Materials And Methods}

This cross-sectional study enrolled 100 children aged older than six years who fulfilled the 2004 revised International League of Associations for Rheumatology Classification for JIA and were evaluated at the Department of Rheumatology, Pakistan Institute of Medical Sciences (PIMS), Islamabad, Pakistan, from June 2018 to June 2019 [15]. Patients with comorbidities or other diseases causing arthritis and psychiatric problems, as well as those with Down's syndrome or other cognitive problems, hearing and speech problems, trauma, sepsis, malignancy, bone diseases, dysplasia, or osteomyelitis were excluded. The design of this study was approved by the ethics committee of PIMS, and verbal and written consent was obtained from all JIA patients and their parents before study enrollment.

Physical disability was measured in these children using the Children Health Assessment Questionnaire with Disability Index (CHAQ-DI), with CHAQ-DI scores of 0 to 1, >1 to 2, and >2 indicating mild, moderate, and severe disability, respectively. Depression was evaluated using the Center for Epidemiological Studies Depression Scale for Children (CES-DC), a 20-item, self-reported inventory of depression with possible scores ranging from 0 to 60 . Cumulative CES-DC scores $<15$ indicated no depression, whereas scores $\geqslant 15$ indicated significant depression. Effect modifiers, including age, gender, eye involvement, disease duration, and presence of antibodies directed against the Fc portion of immunoglobulin $\mathrm{G}$ (rheumatoid arthritis factor - RAF) and antinuclear antibodies (ANA) detected via indirect immunofluorescence on Hep- 2 cell lines controlled by stratification. We used post-stratification chi-square tests, with p-values $<0.05$ considered statistically significant.

\section{Results}

The 100 patients included 54 male patients (mean age, $16.3 \pm 4.9$ years) and 46 female patients (mean age, $18.6 \pm 5.1$ years). Mean duration of disease in the total study population found to be $6.63 \pm 4.67$ years, while most of the patient (44\%) was presented with less than five years of disease duration. Eye involvement was positive in $29 \%$ of the patients. Detailed demographic characteristics of the study population are summarized in Table 1 and Table 2.

\begin{tabular}{|c|c|c|}
\hline Variable & Mean & Standard Deviation ( \pm ) \\
\hline Age (years) & 17.39 & 5.09 \\
\hline Duration of disease (years) & 6.63 & 4.67 \\
\hline Total no. of swollen joints & 6.81 & 6.29 \\
\hline Total no. of tender joints & 6.38 & 7.23 \\
\hline JADAS-27 & 19.92 & 13.81 \\
\hline CHAQ Score & 0.60 & 0.51 \\
\hline CES-DS Score & 23.64 & 12.70 \\
\hline
\end{tabular}

\section{TABLE 1: Demographic and clinical characteristics of the study population $(n=100)$}

JADAS - Juvenile Arthritis Disease Activity Score; CHAQ - Childhood Health Assessment Questionnaire; CES-DS - Center for Epidemiological Studies Depression Scale for Children 


\section{Cureus}

\begin{tabular}{|c|c|c|c|}
\hline Variable & & Frequency & Percentage \\
\hline \multirow{2}{*}{ Gender } & Male & 54 & 54 \\
\hline & Female & 46 & 46 \\
\hline \multirow{2}{*}{ Eye involvement } & Positive & 29 & 29 \\
\hline & Negative & 71 & 71 \\
\hline \multirow{2}{*}{ RAF } & Positive & 19 & 19 \\
\hline & Negative & 81 & 81 \\
\hline \multirow{2}{*}{ ANA } & Positive & 11 & 11 \\
\hline & Negative & 89 & 89 \\
\hline \multirow{3}{*}{ Disease duration } & $<5$ Years & 44 & 44 \\
\hline & 5-10 Years & 37 & 37 \\
\hline & $>10$ Years & 19 & 19 \\
\hline \multirow{3}{*}{ Age group } & $\leq 15$ Years & 35 & 35 \\
\hline & 15-20 Years & 34 & 34 \\
\hline & $>20$ Years & 31 & 31 \\
\hline
\end{tabular}

TABLE 2: Frequency and percentages of demographic and clinical characteristics of the study population $(n=100)$

RAF - rheumatoid arthritis factor; ANA - antinuclear antibodies

Study results illustrated that the mean CES-DC score in the total study sample was $23.64 \pm 12.70$, while CHAQ-DI Score noted as $0.6031 \pm .5150$. As per recorded CES-DC score, it has been elaborated that 72 of the 100 patients with JIA had significant depression. Of these 72 patients, 50 (69.4\%) had mild, 21 (29.2\%) patients had moderate, and one (1.4\%) had severe disability according to CHAQ-DI criteria, with analysis showing a statistically significant relationship between depression and severity of disease $(\mathrm{p}=0.004)$. Age was the only effect modifier that was significantly associated with significant depression in JIA patients $(\mathrm{p}<$ 0.05; Table 3). 


\section{Cureus}

\begin{tabular}{|c|c|c|c|c|c|}
\hline \multirow{2}{*}{\multicolumn{2}{|c|}{ Socio-demographic factors }} & \multicolumn{2}{|c|}{ Significant depression } & \multirow{2}{*}{ Total } & \multirow{2}{*}{ p-value (Chi-square test) } \\
\hline & & Absent & Present & & \\
\hline \multirow{3}{*}{ Gender } & & $35.2 \%$ & $64.8 \%$ & $100.0 \%$ & \multirow{3}{*}{0.083} \\
\hline & \multirow{2}{*}{ Female } & 9 & 37 & 46 & \\
\hline & & $19.6 \%$ & $80.4 \%$ & $100.0 \%$ & \\
\hline \multirow{4}{*}{ Eye involvement } & & 7 & 22 & 29 & \multirow{4}{*}{0.583} \\
\hline & & $24.1 \%$ & $75.9 \%$ & $100.0 \%$ & \\
\hline & \multirow{2}{*}{ Negative } & 21 & 50 & 71 & \\
\hline & & $29.6 \%$ & $70.4 \%$ & $100.0 \%$ & \\
\hline \multirow{4}{*}{ RAF } & & 2 & 17 & 19 & \multirow{4}{*}{0.059} \\
\hline & Positive & $10.5 \%$ & $89.5 \%$ & $100.0 \%$ & \\
\hline & \multirow{2}{*}{ Negative } & 26 & 55 & 81 & \\
\hline & & $32.1 \%$ & $67.9 \%$ & $100.0 \%$ & \\
\hline \multirow{4}{*}{ ANA } & & 4 & 7 & 11 & \multirow{4}{*}{0.513} \\
\hline & Positive & $36.4 \%$ & $63.6 \%$ & $100.0 \%$ & \\
\hline & \multirow{2}{*}{ Negative } & 24 & 65 & 89 & \\
\hline & & $27.0 \%$ & $73.0 \%$ & $100.0 \%$ & \\
\hline \multirow{6}{*}{ Disease duration } & \multirow{2}{*}{$<5$ Years } & 14 & 30 & 44 & \multirow{6}{*}{0.674} \\
\hline & & $31.8 \%$ & $68.2 \%$ & $100.0 \%$ & \\
\hline & \multirow{4}{*}{$>10$ Years } & 10 & 27 & 37 & \\
\hline & & $270 \%$ & $730 \%$ & & \\
\hline & & 4 & 15 & 19 & \\
\hline & & $21.1 \%$ & $78.9 \%$ & $100.0 \%$ & \\
\hline \multirow{6}{*}{ Age group } & & 15 & 20 & 35 & \multirow{6}{*}{0.042} \\
\hline & $\leq 15$ Years & $42.9 \%$ & $57.1 \%$ & $100.0 \%$ & \\
\hline & & 8 & 26 & 34 & \\
\hline & 15-20 Years & $23.5 \%$ & $76.5 \%$ & $100.0 \%$ & \\
\hline & \multirow{2}{*}{$>20$ Years } & 5 & 26 & 31 & \\
\hline & & $16.1 \%$ & $83.9 \%$ & $100.0 \%$ & \\
\hline
\end{tabular}

TABLE 3: Stratification of depression in JIA patients on the basis of different sociodemographic factors

RAF - rheumatoid arthritis factor; ANA - antinuclear antibodies; JIA - juvenile idiopathic arthritis

\section{Discussion}

JIA is a not uncommon disorder in Pakistani children, with $60 \%$ to $80 \%$ of these children having polyarthritis and oligoarthritis, the most common subtypes of JIA [16, 17]. Social disturbances, pain, and deformities in children with JIA can cause psychological distress, with higher proportions of children and adolescents with JIA having significantly higher levels of depression than healthy individuals of the same age and gender [1820]. 
The goal of this cross-sectional study was to assess the prevalence of depression in local children and adolescents with JIA and to evaluate the relationship of depression with disease severity and other effect modifiers. Studies worldwide have reported that children with JIA are prone to the development of psychosocial problems like depression. We found that the prevalence of significant depression in JIA patients was $72 \%$, and that age group was the only effect modifier associated with significant depression. We also observed a statistically significant relationship between the degree of disease, as determined by CHAQ scores, and significant depression in this study population, a finding in agreement with a similar study in Egyptian children with JIA [21].

Complications faced by children with JIA in performing their daily school and recreational activities may cause them to feel different than their healthy peers, which may alter their mood. Although many studies have found that pain was significantly correlated with symptoms of depression in these patients, other studies have reported no significant relationship between depression and pain symptoms [21-23]. Moreover, significant depressive symptoms in children with JIA were found to be comparable to reference scores [24].

A cross-sectional study of the relationship between JIA and depression found that pain scores, disease duration, and CHAQ scores correlated significantly [10]. In contrast, our study did not show a statistically significant relationship between disease duration and depression. A study analyzing the long-term impact of JIA on the psychosocial life of a Greek population showed that disease activity correlated significantly with a higher degree of depression $(p=0.032)[25]$.

The level of depression in the present study population was higher than that in previous studies. For example, a long-term follow-up study of patients with JIA found that the incidence of depression was only $5.2 \%$ [26], with another study finding that depression was present in $31 \%$ of JIA patients [27]. In contrast, this study reported significant depression in $72 \%$ of children with JIA.

The main strength of this study was its evaluation of the association between depressive symptoms and JIA in a pediatric population in a developing country. However, this study had several limitations, including the relatively small number of patients, with most of the population belonging to the same geographic and ethnic group. Large-scale studies that include patients at multiple centers throughout the country are required.

\section{Conclusions}

We carried out a cross-sectional survey to determine the prevalence of depression in children with JIA, at a tertiary care hospital. Physical disability and depression were measured using standardized tools. A high percentage of children with JIA were found to have depressive symptoms, which were significantly associated with the severity of JIA. Depression was significantly associated with age group but not with gender, eye involvement, RAF, ANA, or disease duration. These results emphasize the need to initiate early and prompt measures to prevent depression in this population, and in reducing overall morbidity in patients with JIA.

\section{Additional Information \\ Disclosures}

Human subjects: Consent was obtained by all participants in this study. Animal subjects: All authors have confirmed that this study did not involve animal subjects or tissue. Conflicts of interest: In compliance with the ICMJE uniform disclosure form, all authors declare the following: Payment/services info: All authors have declared that no financial support was received from any organization for the submitted work. Financial relationships: All authors have declared that they have no financial relationships at present or within the previous three years with any organizations that might have an interest in the submitted work. Other relationships: All authors have declared that there are no other relationships or activities that could appear to have influenced the submitted work.

\section{Acknowledgements}

The authors thank Professor Wajahat Aziz, consultant rheumatologist and head of department at the Department of Rheumatology of PIMS, Islamabad, for his support and encouragement throughout the project. We also acknowledge our families and friends for their continuous support and motivation, as well as all the patients and their guardians who participated in this study.

\section{References}

1. Ravelli A, Martini A: Juvenile idiopathic arthritis. Lancet. 2007, 369:767-778. 10.1016/S01406736(07)60363-8

2. Giancane G, Consolaro A, Lanni S, Davì S, Schiappapietra B, Ravelli A: Juvenile idiopathic arthritis diagnosis and treatment. Rheumatol Ther. 2016, 3:187-207. 10.1007/s40744-016-0040-4

3. Kahn P: Juvenile idiopathic arthritis: an update for the clinician . Bull NYU Hosp Jt Dis. 2012, 70:152-166.

4. Helmick CG, Felson DT, Lawrence RC, et al.: Estimates of the prevalence of arthritis and other rheumatic 
conditions in the United States. Part I. Arthritis Rheum. 2008, 58:15-25. 10.1002/art.23177

5. Gowdie PJ, Tse SM: Juvenile idiopathic arthritis. Pediatr Clin North Am. 2012, 59:301-327. 10.1016/j.pcl.2012.03.014

6. Prakken B, Albani S, Martini A: Juvenile idiopathic arthritis. Lancet. 2011, 377:2138-2149. 10.1016/s01406736(11)60244-4

7. Gowa MA, Ibrahim MN, Memon BN, Raza SJ: A cross sectional study on juvenile idiopathic arthritis in paediatric population. J Pak Med Assoc. 2015, 65:370-373.

8. Korte-Bouws GAH, Albers E, Voskamp M, et al.: Juvenile arthritis patients suffering from chronic inflammation have increased activity of both IDO and GTP-CH1 pathways but decreased BH4 efficacy: Implications for well-being, including fatigue, cognitive impairment, anxiety, and depression. Pharmaceuticals. 2019, 12:9. 10.3390/ph12010009

9. Butbul Aviel Y, Stremler R, Benseler SM, et al.: Sleep and fatigue and the relationship to pain, disease activity and quality of life in juvenile idiopathic arthritis and juvenile dermatomyositis. Rheumatology. 2011, 50:2051-2060. 10.1093/rheumatology/ker256

10. Tarakci E, Yeldan I, Kaya Mutlu E, Baydogan SN, Kasapcopur O: The relationship between physical activity level, anxiety, depression, and functional ability in children and adolescents with juvenile idiopathic arthritis. Clin Rheumatol. 2011, 30:1415-1420. 10.1007/s10067-011-1832-0

11. Memari AH, Chamanara E, Ziaee V, Kordi R, Raeeskarami SR: Behavioral problems in juvenile idiopathic arthritis: A controlled study to examine the risk of psychopathology in a chronic pediatric disorder. Int J Chronic Dis. 2016, 5726236:10.1155/2016/5726236

12. Anthony KK, Bromberg MH, Gil KM, Schanberg LE: Parental perceptions of child vulnerability and parent stress as predictors of pain and adjustment in children with chronic arthritis. Child Health Care. 2011, 40:53-69.

13. Abdul-Sattar AB, Elewa EA, El-Shahawy Eel-D, Waly EH: Determinants of health-related quality of life impairment in Egyptian children and adolescents with juvenile idiopathic arthritis: Sharkia Governorate. Rheumatol Int. 2014, 34:1095-1101. 10.1007/s00296-014-2950-1

14. Fair DC, Rodriguez M, Knight AM, Rubinstein TB: Depression and anxiety in patients with juvenile idiopathic arthritis: current insights and impact on quality of life, a systematic review. Open Access Rheumatol. 2019, 11:237-252. 10.2147/OARRR.S174408

15. Petty RE, Southwood TR, Manners P, et al.: International League of Associations for Rheumatology classification of juvenile idiopathic arthritis: second revision, Edmonton, 2001. J Rheumatol. 2004, 31:390392.

16. Naz S, Mushtaq A, Rehman S, Bari A, Maqsud A, Khan MZ, Ahmad TM: Juvenile rheumatoid arthritis. J Coll Physicians Surg Pak. 2013, 23:409-421.

17. Nawaz Z, Shahzad F, Aziz S: Juvenile arthritis disease activity score in children with juvenile idioprthic arthritis and its association with clinical disease in Lahore. Pakistan Armed Forces Med J. 2018, 68:12491255.

18. Kayan Ocakoglu B, Karaca NE, Ocakoglu FT, Erermis S: Psychological burden of pediatric primary immunodeficiency. Pediatr Int. 2018, 60:911-917. 10.1111/ped.13675

19. Castaneda AE, Tuulio-Henriksson A, Aronen ET, Marttunen M, Kolho KL: Cognitive functioning and depressive symptoms in adolescents with inflammatory bowel disease. World J Gastroenterol. 2013, 19:1611-1617. 10.3748/wjg.v19.i10.1611

20. Kuburovic NB, Pasic S, Susic G, et al.: Health-related quality of life, anxiety, and depressive symptoms in children with primary immunodeficiencies. Patient Prefer Adherence. 2014, 8:323-330. 10.2147/PPA.S58040

21. El-Najjar AR, Negm MG, El-Sayed WM: The relationship between depression, disease activity and physical function in juvenile idiopathic arthritis patients in Zagazig University Hospitals-Egypt. Egypt Rheumatol. 2014, 36:145-150. 10.1016/j.ejr.2014.01.001

22. Vuorimaa H, Tamm K, Honkanen V, Komulainen E, Konttinen YT, Santavirta N: Pain in juvenile idiopathic arthritis-a family matter. Childrens Health Care. 2011, 40:34-52. 10.1080/02739615.2011.537937

23. Bromberg MH, Gil KM, Schanberg LE: Daily sleep quality and mood as predictors of pain in children with juvenile polyarticular arthritis. Health Psychol. 2012, 31:202-209. 10.1037/a0025075

24. Miller M, Yan Y, Lales G: Symptoms of depression and anxiety in children with JIA: Relation to other domains of health related quality of life. Arthritis Rheumatol. 2017, 69:2315.

25. Dimopoulou D, Trachana M, Pratsidou-Gertsi P, Garyfallos G, Sidiropoulos P, Theodoridou A, Garyfallos A: Long-term impact of juvenile idiopathic arthritis in the Greek adults' psychosocial life . Pediatr Rheumatol. 2014, 12:P191. 10.1186/1546-0096-12-S1-P191

26. Packham JC, Hall MA, Pimm TJ: Long-term follow-up of 246 adults with juvenile idiopathic arthritis: predictive factors for mood and pain. Rheumatology. 2002, 41:1444-1449. 10.1093/rheumatology/41.12.1444

27. Erdogdu D, Kasapcopur O, Cimen G, Arisoy N, Kayaalp L: Depression, anxiety and pain in juvenile idiopathic arthritis. Pediatr Rheumatol. 2008, 6:P175. 10.1186/1546-0096-6-S1-P175 